\title{
Dim2p, a KH-domain protein required for small ribosomal subunit synthesis
}

\author{
EMMANUEL VANROBAYS, ${ }^{1,2}$ JEAN-PAUL GÉLUGNE, ${ }^{2}$ MICHÈLE CAIZERGUES-FERRER, $^{2}$ and \\ DENIS L.J. LAFONTAINE ${ }^{1}$ \\ ${ }^{1}$ F.N.R.S., Université Libre de Bruxelles, Institut de Biologie et de Médecine Moléculaires, Charleroi-Gosselies, Belgium \\ ${ }^{2}$ LBME du CNRS, 31062 Toulouse cedex 04, France
}

\begin{abstract}
Recent proteomic analyses are revealing the dynamics of preribosome assembly. Following cleavage at processing site $A_{2}$, which generates the 20S pre-rRNA (the immediate precursor to the 18S rRNA), early RRPs (ribosomal RNA processing factors) are released in bulk from the preribosomes, and the resulting pre-40S subunits are left associated with a limited set of proteins that we refer to as the SSU RRP complex. Dim2p, a core constituent of the SSU RRP complex and conserved KH-domain containing protein, is required for pre-rRNA processing and is associated with early nucleolar and late cytoplasmic pre-rRNA species. Consistently, Dim2p shuttles between the nucle(ol)us and the cytoplasm, a trafficking that is tightly regulated by growth. The association of Dim2p with the 18S rRNA dimethyltransferase Dim1p, as well as its requirement for pre-rRNA processing at cleavage sites $A_{1}$ and $A_{2}$ and for $18 S$ rRNA dimethylation, suggest that Dim2p may recruit Dim1p to nucleolar pre-rRNAs through its $\mathrm{KH}$ domain.
\end{abstract}

Keywords: ribosome synthesis; pre-rRNA processing; KH-domain; nucleolus

\section{INTRODUCTION}

Ribosome biogenesis involves the synthesis, maturation, and assembly of four ribosomal RNAs (rRNAs) and $\sim 80$ ribosomal proteins (RPs). Mature rRNAs are generated from pre-rRNA precursors following a complex succession of endo- and exoribonucleolytic digestions (Fig. 1; for review, see Kressler et al. 1999; Venema and Tollervey 1999), specific residues are selected for ribose or base modification, and preribosomes are assembled from pre-rRNAs and RPs (for review, see Lafontaine and Tollervey 2001). The sites of RNA modification are largely selected through WatsonCrick base-pair interactions with members of conserved families of small nucleolar RNAs (snoRNAs; for review, see Kiss 2002). Preribosomes are released from the nucleolus, where most of these steps occur; diffuse through the nucleoplasm; and exit the nucleus through the nuclear pore complexes. Small and large ribosomal subunits transit to the cytoplasm independently.

A basic scheme for ribosomal assembly, based on in vivo labeling and velocity gradients analysis, was established in the early 1970s (Udem and Warner 1973; Trapman et al.

Reprint requests to: Denis L.J. Lafontaine, ULB-IBMM, Rue des Profs Jeener \& Brachet 12, B-6041 Charleroi-Gosselies, Belgium; e-mail: Denis.lafontaine@ulb.ac.be; fax: 32-2-650-9747.

Article and publication are at http://www.rnajournal.org/cgi/doi/ 10.1261/rna.5162204.
1975). In this, a $90 \mathrm{~S}$ particle, based on the RNA polymerase $\mathrm{I}$ (Pol I) primary transcript (35S in yeast), is converted into $43 \mathrm{~S}$ and $66 \mathrm{~S}$ preribosomes, precursors to the small and large ribosomal subunits, respectively. This vision remained unchallenged for more than three decades.

The recent development of new proteomic technologies has poised the field for rapid progress and led to the detailed characterization of several dozen species of nucle(ol)ar and cytoplasmic preribosomes (for review, see Fatica and Tollervey 2002; Lafontaine, Raue 2003; Tschochner and Hurt 2003). The large Pol I transcript is now known to be primarily bound by $>30$ RRPs, most of which almost exclusively involved in early pre-rRNA processing reactions and Small ribosomal SUbunit (SSU) synthesis. These 90S preribosomes largely overlap in composition with the recently described SSU processome, imaged as terminal balls on chromatin spreads and corresponding to the box C/D snoRNP U3 (Dragon et al. 2002; Grandi et al. 2002). Following cleavage at site $\mathrm{A}_{2}$, which generates the $20 \mathrm{~S}$ and $27 \mathrm{SA}_{2}$ pre-rRNAs (Fig. 1), precursors to the small and large subunit rRNAs, the $90 \mathrm{~S}$ preribosomes break up and the first set of $>30$ RRPs are released in bulk. The resulting pre-40S subunits are left associated with very few RRPs and acquire a limited number of novel factors. In fact, only eight major nonribosomal proteins are detected in nucle(ol)ar $40 \mathrm{~S}$ preribosomes (Schafer et al. 2003), Rrp12p, Tsr1p (a putative GTPase related to Bms1p; Gelperin et al. 2001; Wegierski et 
al. 2001), Enplp (Chen et al. 2003), Hrr25p, Nob1p, Rio2p (a putative protein kinase homologous to Riolp; Vanrobays et al. 2001, 2003), Dimlp (a base methyltransferase; Lafontaine et al. 1995, 1998), and Dim2p/Yor145c (a KH-domain protein). Ltv1p, Nop14p/Noc5p, and Asc1p are also present but in substoichiometric amounts. We will hereafter refer to this protein set as the SSU RRP complex (Table 1). The kinetics of association of the various constituent of the SSU RRP complex with the pre-40S particles is distinctively different with Enp1p, Dim1p, Hrr25p and possibly Rrp12p binding to the pre-rRNAs at an early nucleolar stage, corresponding to the $90 \mathrm{~S}$ preribosomes, and Noblp, Rio2p, and Tsrlp associating later, after cleavages at sites $\mathrm{A}_{0}-\mathrm{A}_{2}$ (Schafer et al. 2003). Most constituents of the SSU RRP complex have known functions in $40 \mathrm{~S}$ subunit synthesis (Lafontaine et al. 1995; Gelperin et al. 2001; Liu and Thiele 2001; Ihmels et al. 2002; Chen et al. 2003; Fatica et al. 2003; Schafer et al. 2003; Vanrobays et al. 2003).

The $\mathrm{K}$ homology $(\mathrm{KH})$-domain is a 45-amino-acid RNA-binding motif based on a nine-residues consensus (VIGxxGxxI). It is highly conserved and has been detected in all three domains of life (Gibson et al. 1993b; Siomi et al. 1993; Burd and Dreyfuss 1994; Adinolfi et al. 1999; Grishin 2001). A single amino acid substitution (I304N) in the $\mathrm{KH}$ domain of FMR1 led to fragile $\mathrm{X}$ syndrome, the most common cause of human hereditary mental retardation (De Boulle et al. 1993; Gibson et al. 1993a; Siomi et al. 1994).

Here, we report the functional characterization of Yor145c/Dim2p, a KH domain protein required for SSU synthesis and core component of the SSU RRP complex.

\section{RESULTS}

\section{A late SSU RRP network}

Recent proteomic analysis identified a network of physical interactions connecting about a dozen of proteins, most of which are known RRPs involved in small ribosomal subunit synthesis (Fig. 2; Table 1). Figure 2 was compiled from high-throughput copurification data sets (Gavin et al. 2002; Ho et al. 2002; Schafer et al. 2003; Vazquez et al. 2003). According to Samanta and Liang, Yor $145 \mathrm{c}$ shares a statistically relevant number of common partners with Dimlp, defining a couple of "close functional partners" with potential related functions (cited in Vazquez et al. 2003). Yor145c was thus renamed Dim2p. Dim2p had not been tested for a function in ribosome synthesis when this work was initiated.

\section{Dim2p is a conserved KH-domain protein homologous to Krr1p}

Blast analysis revealed that Dim2p is a conserved $\mathrm{KH}$ domaincontaining protein with members throughout the archaeal and eukaryal domains (Fig. 3A). The most conserved residues of the $\mathrm{KH}$ domain, involved in RNA binding (for review, see
A.

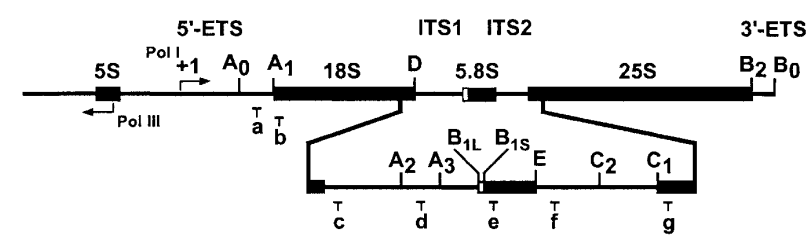

B.

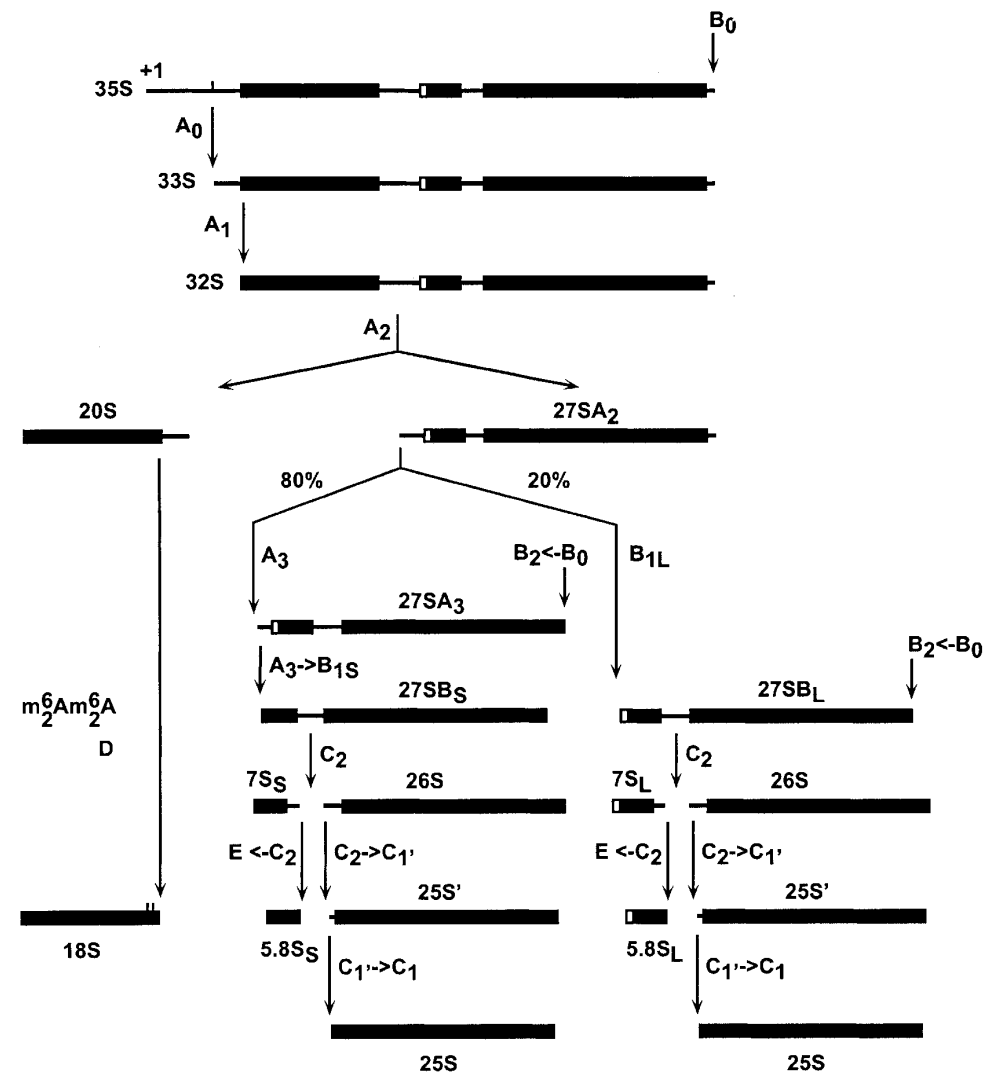

c.

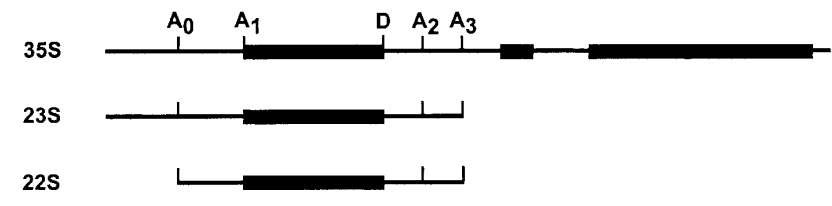

FIGURE 1. (Legend on next page) 
TABLE 1. Major components of the SSU RRP complex

\begin{tabular}{llll}
\hline Names & \multicolumn{1}{c}{ Protein motifs, functions } & Pre-rRNA processing defect & References \\
\hline Dim1p/Ypl266c & SAM binding motif Base methyl-transferase & $\mathrm{A}_{1}, \mathrm{~A}_{2}$ & Lafontaine et al. (1995) \\
Dim2p/Yor145c & KH motif, RNA binding, homology to Krr1p & $\mathrm{A}_{1}, \mathrm{~A}_{2}$ & This work \\
Enp1p/Ybr247c & - & $\mathrm{A}_{0}, \mathrm{~A}_{1}, \mathrm{~A}_{2}$ & Chen et al. (2003) \\
Hrr25p/Ypl204w & protein kinase, a subunit of CK1 & Not determined & - \\
Nob1p/Yor056c & PIN motif, putative phosphodiesterase & $\mathrm{A}_{0}, \mathrm{~A}_{1}, \mathrm{~A}_{2}, \mathrm{D}$ & Fatica et al. (2003) \\
Rio2p/Ynl207w & RIO domain, putative protein kinase & $\mathrm{D}$ with marginal effects on & Vanrobays et al. (2003) \\
Rrp12p/Ypl012w & - & $\mathrm{A}_{0}, \mathrm{~A}_{1}, \mathrm{~A}_{2}$ & - \\
Tsr1p/Ydl060w & Homology to the GTPase Bms1p but without the P-loop & $\mathrm{A}_{0}, \mathrm{~A}_{1}, \mathrm{~A}_{2}, \mathrm{D}$ & Gelperin et al. (2001) \\
\hline
\end{tabular}

Adinolfi et al. 1999), are detected in Dim2p (Fig. 3B). Striking homology with Krrlp, a eukaryotic-specific SSU RRP (Sasaki et al. 2000; Chan et al. 2001), indicates that these two proteins presumably derived from a common ancestor (Fig. 3A). Krrlp and Dim2p are conserved in minimal eukaryotic genomes such as those of Giardia (12 Mb) and Encephalitozooan $\mathrm{cu}$ niculi (3 Mbp), attesting of the early divergence of these genes.

Within archaeal genomes, DIM2 is closely linked to RIO1, another SSU RRP (Vanrobays et al. 2001), suggesting a possible coregulation for expression and the existence of an operon (Fig. 3C). In Archaea, DIM2 and RIO1 are either organized in a head-to-head or head-to-tail fashion, and in some species, these two open reading frames show striking overlaps. TIF11, involved in ribosome function, is also closely linked to these genes.

\section{Dim2p shows a surprisingly dynamic subcellular distribution}

The subcellular distribution of $\operatorname{Dim} 2 p$ was investigated in strains expressing a fluorescent construct and directly im- aged in living cells (Fig. 4). A C-terminal GFP cassette was integrated on the chromosome at the DIM2 locus by PCR. The epitope-tagged construct was fully functional, as shown by its ability to rescue growth to wild-type levels (data not shown). A diploid strain, homozygous for the DIM2-GFP allele, was used in the localization studies for improved detection of the fluorescent signal.

A culture was inoculated in complete glucose-based medium (YPD), and cells were observed at regular intervals, starting at early-log to stationary phases of growth (Fig. 4A); growth was monitored by $\mathrm{OD}_{600}$ (Fig. 4B). Cells were counter-stained with DAPI to localize the DNA. In yeast, the nucleolus is typically detected as a crescent-shaped structure facing the chromosomal DNA.

Unexpectedly, Dim2p-GFP showed a particularly dynamic subcellular distribution. At early log-phase, Dim2p was detected both in the cytoplasm and nucleus, with a significant enrichment corresponding to the nucleolus. As cells progressed through the exponential phase of growth, $\operatorname{Dim} 2 \mathrm{p}$ was progressively depleted from the cytoplasm and concentrated in the nucleus and nucleolus. When cells reached saturation, $\operatorname{Dim} 2 \mathrm{p}$ was only found as a bright nucleolar focus (Fig. $4 \mathrm{~A}$, stationary).

To investigate the dynamics of this subcellular redistribution, starved cells were diluted to fresh medium and allowed to grow for several generations (Fig. 4C). The nuclear distribution was regained within $5 \mathrm{~min}$; an equal distribution between the nucleus and the cytoplasm was restored after $1 \mathrm{~h}$. This suggested that Dim $2 p$ shuttles between the nucleus and the cytoplasm, an assumption that recently turned out to be correct (Schafer et al. 2003).

\section{Dim2p colocalizes with pre-40S subunits and $90 \mathrm{~S}$ preribosomes}

Total cellular extracts were prepared from cells expressing a Dim2p-GFP con- 


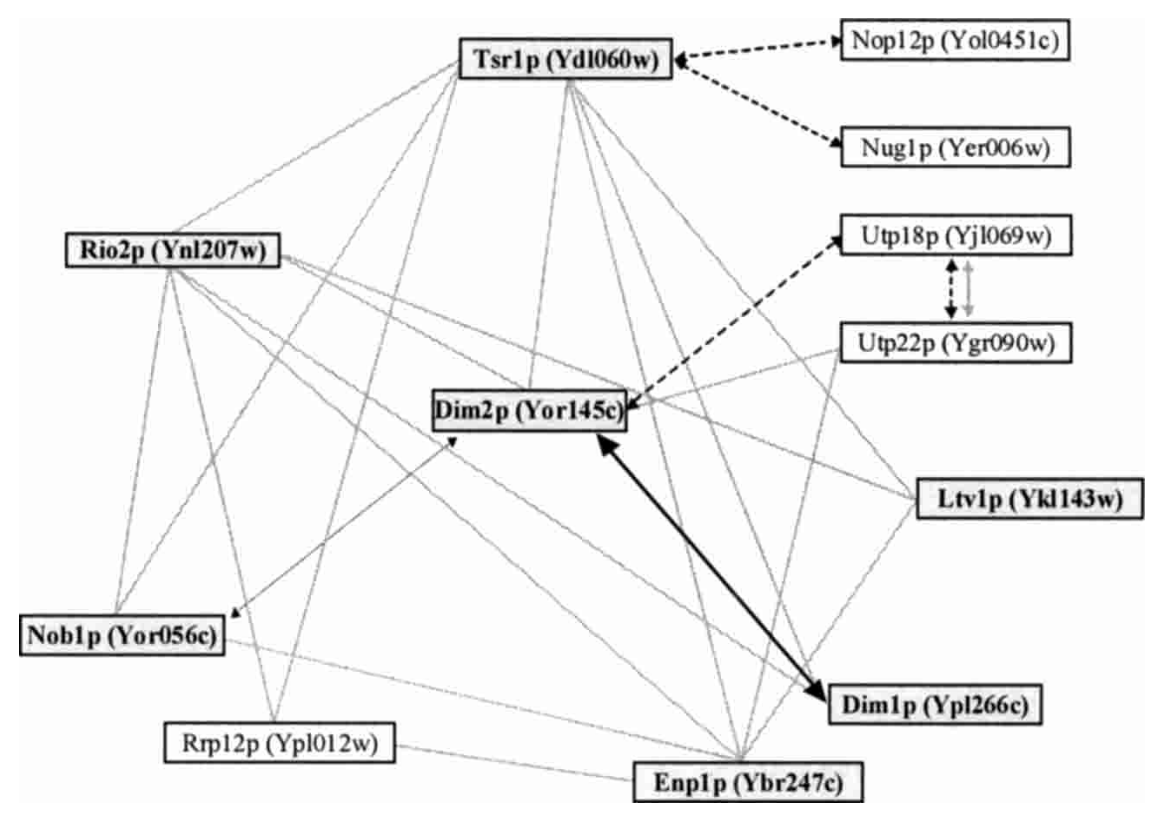

FIGURE 2. The SSU RRP network. Physical and functional interactions between components of the SSU RRP complex. Following pre-rRNA processing at sites $\mathrm{A}_{0}-\mathrm{A}_{2}$, 20S-based preribosomes (or pre-40S subunits) are generated that are only associated with about a dozen of RRPs that we propose to refer to as the SSU RRP complex. Interactions between the various components of the SSU RRP complex are from as follows: in grey, Gavin et al. (2002); dashed lines, Ho et al. (2002); and dotted line, Tone and Toh (2002). Components in bold were identified in complexes recently described by Schafer et al. (2003). The interaction between Dimlp and Dim2p is from this work.

struct and fractionated on $10 \%-30 \%$ glycerol gradients (Fig. 4D). Total RNA was extracted, separated on agarose/ formaldehyde gels, and stained with ethidium bromide to position the peaks corresponding to $40 \mathrm{~S}, 60 \mathrm{~S}$, and monosomes (data not shown). Proteins were extracted, resolved on PAGE, and transferred to nitrocellulose for Western-blot hybrization. Antibodies specific to ribosomal proteins from both subunits were used as controls. Membranes were hybridized with an antibody specific to the GFP moiety of the Dim2p construct.

In exponentially growing cells, Dim2p was distributed throughout the whole gradient, with a major peak around $40 \mathrm{~S}$ that corresponded to pre- $40 \mathrm{~S}$ subunits and a fraction that colocalized with faster migrating particles, corresponding to $90 \mathrm{~S}$ preribosomes (Fig. 4D, upper panel). This analysis was repeated at later stages of growth, at the transition to stationary (middle panel) and at stationary (lower panel). As observed by fluorescence, Dim2-GFP also showed a dynamic behavior on glycerol gradient. Significantly, Dim2p-GFP was relocated to slower migrating particles that may correspond to proteinaceous intermediates in the preribosome assembly pathway. This distribution was even more striking at the stationary phase of growth. Despite repetitive attempts, the gradient profiles at high $\mathrm{OD}_{600}$ consistently showed an elevated level of proteolysis.

\section{Dim2p is required for pre-rRNA processing}

To test for a potential involvement of Dim2p in ribosome synthesis, a conditional strain was constructed. DIM2 was placed under the control of a GAL::regulated promoter and expressed from a low copy plasmid in a dim $2 \Delta$ background; Dim2p was further fused at its $\mathrm{N}$-terminal end to the Protein A epitope (a twin $\mathrm{Z}$ domain was used), resulting in a GAL::ZZ-dim2 construct. Transcription driven from $G A L::$ promoters is strongly reduced in the presence of glucose in the growth medium.

Galactose-dependent growth was first tested on solid media. $\operatorname{dim} 2 \Delta$ strains expressing either a plasmid-borne wildtype gene or the GAL::ZZ-dim2 fusion were grown in complete medium supplemented with either galactose or glucose (YPGal and YPD, respectively). Growth was only detected in permissive YPGal medium (data not shown); this was as expected for an essential gene (Grava et al. 2000). ZZ-Dim2p was functional as shown by its ability to rescue growth to wild-type levels in YPGal (data not shown).

The kinetics of Dim2p depletion was assessed in liquid medium by Western-blot. Following $10 \mathrm{~h}$ of transfer to the nonpermissive conditions, the growth rate of $G A L:: Z Z$ $\operatorname{dim} 2$ strains was already substantially reduced with a doubling time (DT) $>8 \mathrm{~h}$ (DT was $\sim 2 \mathrm{~h}$ in permissive conditions), and the level of the ZZ-Dim2p fusion detectably affected (data not shown). Growth essentially ceased following $16 \mathrm{~h}$ of transfer. A low level of residual ZZ-Dim $2 \mathrm{p}$ was detected at late depletion time points (data not shown).

Pre-rRNA processing was assessed by Northern-blot hybridization, primer extension, and in vivo labeling (Figs. $5,6)$.

GAL::ZZ-dim2 strains and a wild-type isogenic control were grown in YPGal and transferred to YPD to achieve Dim2p depletion (see above and Material and Methods). Total RNA was extracted at the time points indicated, separated on $1.2 \%$ agarose/formaldehyde gels, and transferred to nylon membranes for Northern-blot analysis. Membranes were hybridized with a collection of oligonucleotide probes specific to various subsets of precursors and mature rRNAs (Fig. 1A).

In wild-type yeast cells, the primary Pol I transcript (35S) is rapidly cleaved in the $5^{\prime}$ external transcribed spacer (5'ETS) at sites $\mathrm{A}_{0}$ and $\mathrm{A}_{1}$ - the $5^{\prime}$ mature end of $18 \mathrm{~S}$ rRNAand in the internal transcribed spacer 1 (ITS1) at site $A_{2}$ (Fig. 1B). Cleavages at sites $A_{0}$ and $A_{1}$ generate the $33 S$ and 


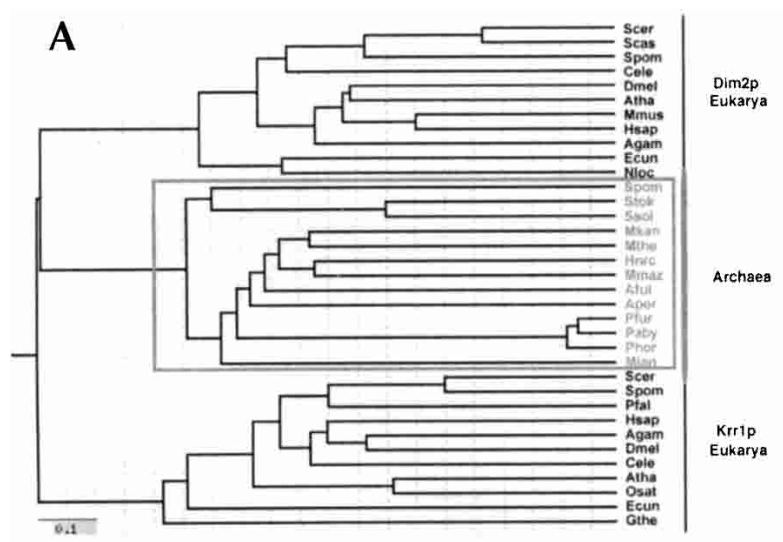

C

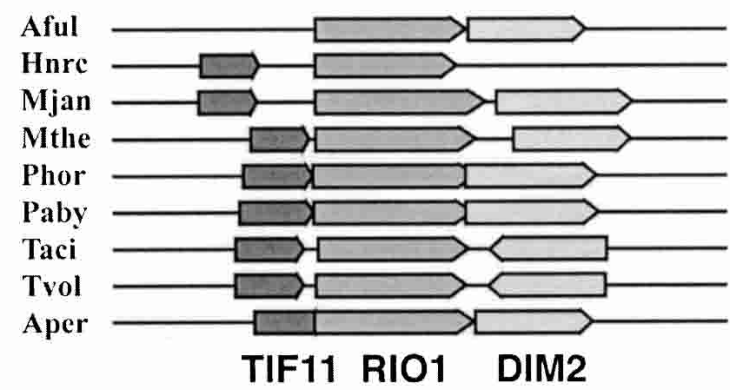

B

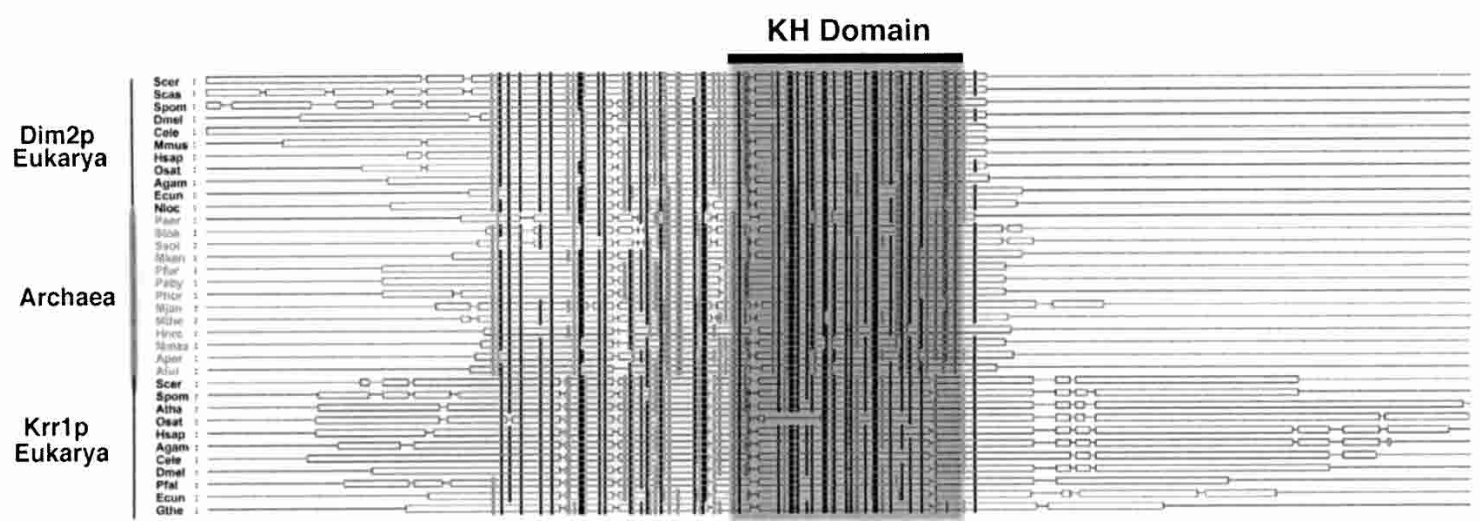

FIGURE 3. Dim2p is a phylogenetically conserved KH-domain containing protein related to the eukaryotic-specific RRP Krrlp. ( $A, B$ ) Phylogenetic analysis and multiple alignments were performed as described in the Material and Methods section. $(A) 0.1$ refers to the divergence index. (B) The KH-domain is highlighted. Residues in grey are $70 \%-90 \%$ similar; residues in black are either identical or show $>90 \%$ similarity. $(C)$ Structure of Archaeal genomes at the DIM2 locus. Species names are as follows: Scer, Saccharomyces cerevisiae; Scas, Saccharomyces casletellii; Spom, Schizosaccharomyces pombe; Dmel, Drosophila melanogaster; Osat, Oryza sativa; Mmus, Mus musculus; Hsap, Homo sapiens; Cele, Caenorhabditis elegans; Agam, Anopheles gambiae; Ecun, Encephalitozoon cuniculi; Nloc, Nosema locustae; Paer, Pyrobaculum aerophilum; Stok, Sulfolobus tokodaii; Mkan, Methanopyrus kandleri; Aper, Aeropyrum pernix; Pfur, Pyrococcus furiosus; Phor, Pyrococcus horikoshii; Paby, Pyrococcus abyssi; Mjan, Methanococcus jannaschii; Aful, Archaeoglobus fuldus; Ssol, Sulfolobus solfataricus; Hnrc, Halobacterium sp. NRC-1; Mmaz, Methanosarcina mazei; Atha, Arabidopsis thaliana; Pfal, Plasmodium falciparum; Mthe, Methanobacterium thermoautotrophicum; Taci, Thermoplasma acidophilum; Tvol, Thermoplasma volcanium; Hnrc, Halobacterium sp. NRC-1; and Gthe, Guillardia theta.

$32 \mathrm{~S}$ pre-rRNAs, respectively. The $32 \mathrm{~S}$ pre-rRNA is cleaved at site $\mathrm{A}_{2}$ to produce the $20 \mathrm{~S}$ and $27 \mathrm{SA}_{2}$ pre-rRNAs, precursors to the small and large ribosomal subunit rRNAs, respectively.

The steady-state level of the 35S, 33S, and $32 \mathrm{~S}$ pre-rRNAs was elevated in cells depleted for Dim2p by comparison to the wild-type isogenic control or to GAL::ZZ-dim2 strains grown in YPGal (Fig. 5A, oligo c, cf. lanes $1-3$ and 4-6), indicating a requirement for Dim $2 p$ in early pre-rRNA processing reactions.

The $20 \mathrm{~S}$ and $27 \mathrm{SA}_{2}$ pre-rRNAs were readily detected in wild-type and $G A L:: Z Z$-dim2 strains grown in permissive conditions; however, both species were strongly under accumulated in Dim2p-depleted cells (Fig. 5A, oligos c and d, cf. lanes 1-3 and 4-6,). Cleavage at $A_{2}$ therefore appeared strongly inhibited in the absence of Dim2p.

Hybridization with oligonucleotide d, specific to a se- quence located between cleavage site $\mathrm{A}_{2}$ and $\mathrm{A}_{3}$, revealed the accumulation of the 22S RNA, an aberrant RNA species that extends between sites $\mathrm{A}_{0}$ and $\mathrm{A}_{3} ; 22 \mathrm{~S}$ RNA accumulation is diagnostic of an inhibition of cleavage at sites $A_{1}$ and $A_{2}$ (Fig. 1C). The 22S RNA is a dead-end intermediate that is not faithfully processed to $18 \mathrm{~S}$ rRNA but rather degraded, presumably by the overlapping exoribonucleolytic activities of the Exosome complex (Allmang et al. 2000).

Hybridization with oligo $c$, which is specific to both the $20 \mathrm{~S}$ pre-rRNA and the 22S RNA, showed that the accumulation of the $22 \mathrm{~S}$ correlates with the depletion of $20 \mathrm{~S}$.

As a direct consequence of the inhibition of cleavage at sites $A_{1}$ and $A_{2}$, the steady-state level of $18 S$ rRNA was substantially reduced in GAL::ZZ-dim2 strains grown in YPD (Fig. 5A, oligo b, cf. lanes 1-3 and 4-6). PhosphorImager quantitation estimated the residual level of $18 \mathrm{~S}$ rRNA to be of only $\sim 5 \%$ of wild-type levels after a depletion 
A.
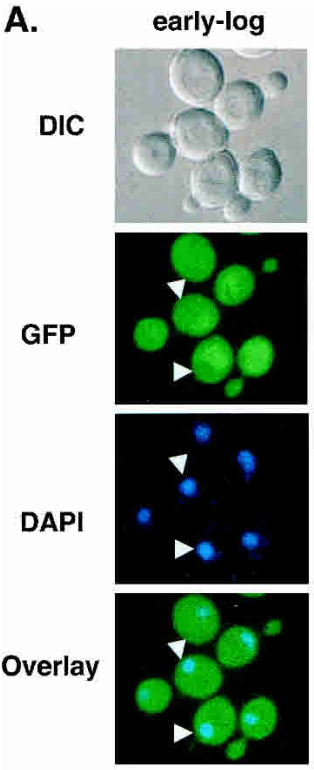

B.

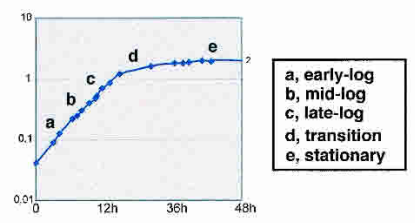

D.
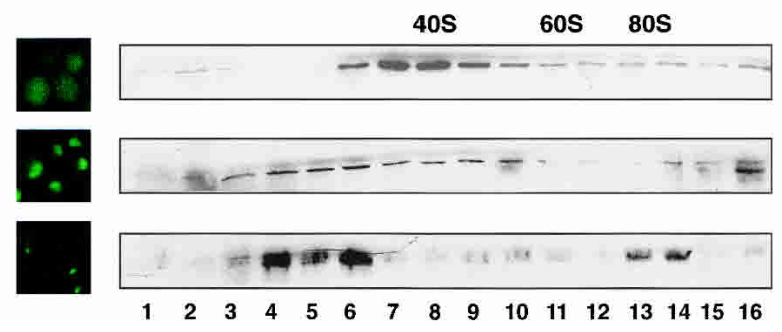

FIGURE 4. Dim2p shows a dynamic subcellular distribution and a dynamic sedimentation profile throughout growth. $(A-C)$ Subcellular distribution throughout growth. Cells expressing a functional Dim2p-GFP construct were inoculated in a complete, glucose-based medium (YPD) and examined for fluorescence under the microscope throughout growth. Cells were counter-stained with DAPI to visualize the bulk DNA. A phase (DIC) is provided. (B) Corresponding growth curve; cell growth was monitored by $\mathrm{OD}_{600} .(C)$ Subcellular distribution dynamics. Cells expressing a Dim2p-GFP construct were grown to stationary phase, diluted to fresh medium, and inspected at regular intervals for $1 \mathrm{~h}$. (D) Sedimentation profile throughout growth. Glass-beads lysates from cells expressing a functional Dim2p-GFP construct at different stages of growth were layered on $10 \%-30 \%$ glycerol gradients. Individual fractions were processed for Western-blot hybridization and decorated with an anti-GFP antibody to visualize the Dim2p-GFP fusion. Mid-log, transition to stationary, and stationary phase of growth (top, middle, and bottom, respectively) were analyzed; fluorescence panels are provided to the left as controls. Hybridization with antibodies specific to the small and large subunits, as well as the analysis of the contents in RNA of each fraction, allowed to position the peaks for 40S, 60S, and monosomes (data not shown).

prolonged for $24 \mathrm{~h}$. By comparison, with the effects reported for other RRPs involved in SSU synthesis, including several core snoRNP components, this defect alone could easily accounts for the growth defect reported.

Processing downstream of cleavage site $\mathrm{A}_{2}$-which mostly concerns the synthesis of large ribosomal subunit
rRNAs - was not greatly affected by the lack of Dim2p, and the steady-state level of the major intermediates involved in 5.8S-25S rRNA synthesis (notably, the $27 \mathrm{SB}$ and $7 \mathrm{~S}$ pre-rRNAs), as well as the mature rRNAs, was essentially unaltered (Fig. 5A, oligos e-g).

A low level of $23 \mathrm{~S}$ RNA, which extends from the transcription start site $(+1)$ to $\mathrm{A}_{3}$, is often detected in wild-type strains, indicating that a fraction of the pre-rRNA molecules is directly cleaved in the ITS1 at site $\mathrm{A}_{3} ; 23 \mathrm{~S}$ was also detected in the absence of Dim2p but was not significantly increased (data not shown).

Concurring evidence for a defect in pre-rRNA processing at sites $A_{1}$ and $A_{2}$ was provided by a thorough primer extension analysis (Fig. 5B). This allowed to examine the steady-state levels of low abundant and/or short-lived RNAs (e.g., $33 \mathrm{~S}, 27 \mathrm{SA}_{3}$ ) and to detect species that are difficult to resolve on agarose gels (e.g., the short and long forms of several pre-rRNAs species; Fig. 1).

Oligonucleotide $\mathrm{b}$, specific to the $5^{\prime}$ end of the 18S rRNA, was extended across the $5^{\prime}$-ETS; cDNA synthesis was specifically blocked at the transcription start site $(+1)$, revealing the steady-state level of the primary transcript, and at site $A_{0}$, corresponding to the $5^{\prime}$ end of the $33 \mathrm{~S}$ pre-rRNA. Primer extension across ITS1 was performed from oligo f; this revealed cleavage at sites $A_{2}, A_{3}$, and $B_{1}$. Alternative processing at site $B_{1}$ generates short and long forms of prerRNAs that differ in length by seven to eight nucleotides (Fig. 1); these were well-resolved by this analysis.

Continuous cleavage at site $\mathrm{A}_{0}$ and inhibition of downstream processing sites were confirmed by a substantially increased signal at this site throughout the course of the depletion (Fig. 5B, cf. lanes $1-3$ and 4-7). The signal corresponding to RNA species ending at $A_{2}$ was strongly codepleted with Dim2p, corroborating the inhibition of cleavage at this site. Cleavage at $A_{3}$ and $B_{1}$ appeared unaffected by the depletion of Dim2p, and the ratio of short versus long forms of the pre-rRNAs $(\sim 8: 2)$ was unaltered. Position of cleavages all appeared conserved at the nucleotide level.

Finally, the kinetics of the pre-rRNA processing defect observed in strains lacking Dim2 $p$ was addressed by in vivo 


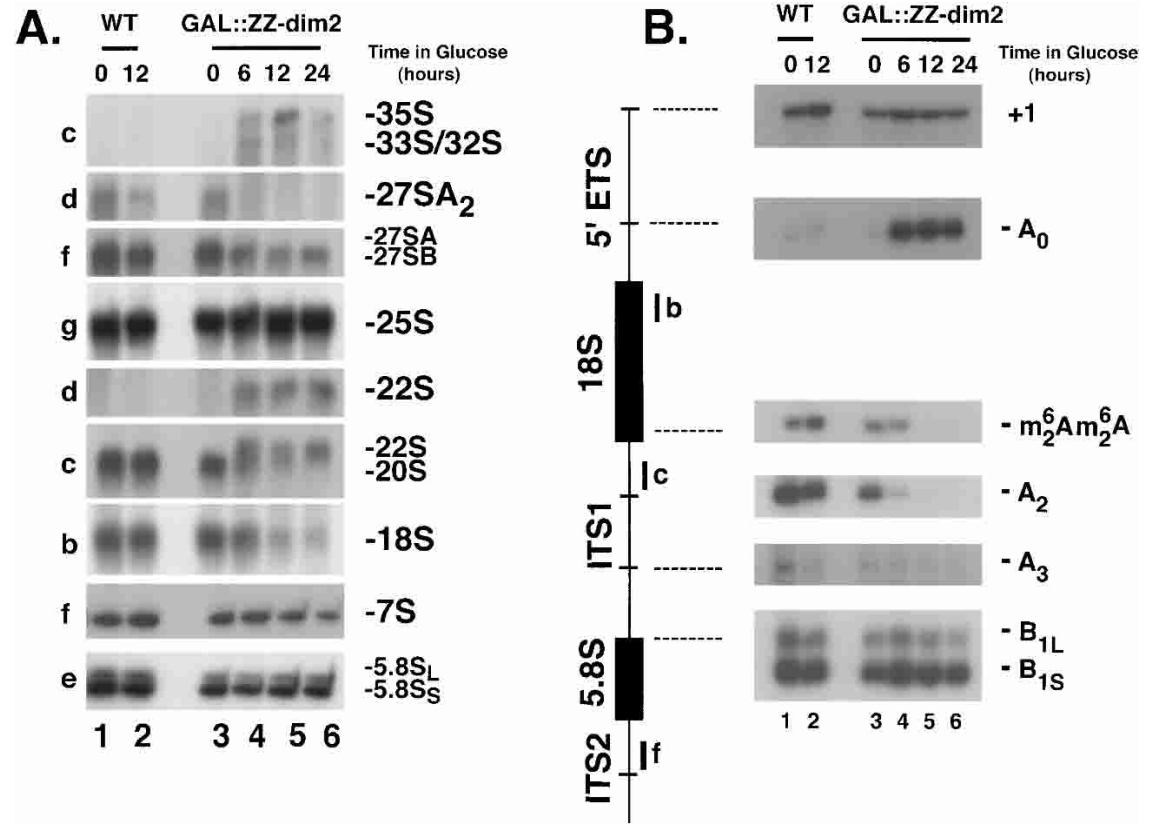

FIGURE 5. Pre-rRNA processing analysis in cells depleted for Dim2p. To achieve Dim2p depletion, a GAL::ZZ-dim2 strain was grown to mid-log phase in permissive conditions (YPGal); cells were thoroughly washed in water and transferred to prewarmed $\left(30^{\circ} \mathrm{C}\right) \mathrm{YPD}$ for up to $24 \mathrm{~h}$. As a control, a wild-type isogenic strain was used. (A) Northern blot analysis. Total RNA was extracted at the time points of transfer indicated, separated on agarose/formaldehyde gels, and transferred to nylon membranes for Northern blot hybridizations. A collection of oligonucleotide probes (Fig. 1A) specific to the pre-rRNAs and rRNAs were used. RNA species are indicated to the right; oligoprobes to the left. (B) Primer extension analysis. cDNA synthesis was initiated from oligonucleotides $b, c$, and $f$ (Fig. 1A). Signals corresponding to the transcription start site $(+1)$, cleavage sites $A_{0}, A_{2}, A_{3}, B_{1 S}$, and $B_{1 L}$, as well as for the base methylation carried out by Dimlp, are indicated.

labeling (Fig. 6). Dim2p was depleted by growing $G A L:: Z Z$ $\operatorname{dim} 2$ cells in a glucose-based minimal medium lacking uracil for $19 \mathrm{~h}$ (see Material and Methods). Cells were pulselabeled for 4 min with tritiated uracil and chased with an excess of cold uracil for up to $20 \mathrm{~min}$. Total RNA was extracted and processed as described above. For comparison, the experiment was performed in galactose in parallel.

In permissive conditions, the primary transcript was rapidly converted to $33 \mathrm{~S}$ and $32 \mathrm{~S}$ pre-rRNAs, and none of these RNA species were detected at the exposure presented in Figure 6 . The $27 \mathrm{~S}$ and $20 \mathrm{~S}$ pre-rRNAs were readily detected and quantitatively chased into $25 \mathrm{~S}$ and $18 \mathrm{~S}$ rRNAs, respectively. In the absence of Dim2p, the $35 \mathrm{~S}, 33 \mathrm{~S}$, and $32 \mathrm{~S}$ pre-rRNAs were stably accumulated, due to their reduced processing rate. Processing of the 27SB precursors also significantly slowed down but with no apparent consequence for the overall accumulation of $25 \mathrm{~S}$ rRNA. No $20 \mathrm{~S}$ prerRNA was detected; rather, the 22S RNA was rapidly accumulated and appeared relatively stable over the time of the chase $(20 \mathrm{~min})$. The $22 \mathrm{~S}$ RNA was not converted to $18 \mathrm{~S}$, leading to a substantial underaccumulation of this RNA.

None of the four snoRNAs involved in early pre-rRNA processing reactions in yeast, the box C/D snoRNAs $\mathrm{U} 3$ and U14 and the box H/ACA snoRNAs snR10 and snR30, were affected for their stability in cells depleted for Dim2p (data not shown).

In conclusion, Dim2p is required for the early pre-rRNA processing reactions at sites $A_{1}$ and $A_{2}$. In the absence of Dim2p, pre-rRNAs are directly cleaved in the ITS1 at site $\mathrm{A}_{3}$, generating the aberrant $22 \mathrm{~S}$ RNA that is no longer processed. Consequently, cells deprived of Dim2p show a strong deficit in $18 \mathrm{~S}$ rRNA, the small ribosomal subunit rRNA.

\section{Dim2p is associated with Dim1p and is required for $18 \mathrm{~S}$ rRNA dimethylation}

Cells depleted for the 18S rRNA dimethyltransferase Dim1p virtually showed an identical pre-rRNA processing defect as those depleted for Dim2p, in particular, the accumulation of the $22 \mathrm{~S}$ aberrant RNA diagnostic of pre-rRNA processing inhibitions at sites $A_{1}$ and $A_{2}$ (Lafontaine et al. 1995, 1998). This prompted us to test for physical and/or functional interactions between the two proteins, that is, to investigate whether $\operatorname{Dim} 2 p$ is associated with Dimlp in vivo and whether Dim2p is required for $18 \mathrm{~S}$ rRNA demethylation.

The association between Dimlp and Dim2p was tested by coprecipitation (Fig. 7A). A total lysate was prepared in $150 \mathrm{mM}$ salts from a ZZ-Dim2p strain transformed with a plasmid expressing a functional $\mathrm{His}_{6}$-Dim1p fusion under the control of its own promoter and incubated with metal affinity resin (see Material and Methods). Aliquots of total (T), supernatant (S), and pellet $(\mathrm{P})$ fractions were loaded on PAGE, treated for Western blot, and decorated with an antibody specific for the protein A moiety of the ZZ-Dim2p fusion. Dim2p was efficiently recovered in the pellet fractions. As a control, the membrane was probed with an antibody specific to glucose6-phosphate dehydrogenase (Zwflp/G6PDH).

The methylation status of pre-rRNAs accumulated in strains depleted for Dim2p was assessed by primer extension (Fig. 5B). cDNA synthesis was initiated from primer $\mathrm{c}$ that is complementary to the $5^{\prime}$-end portion of ITS1; the reverse transcriptase used in this assay was previously shown to be specifically blocked by the modification (Henry et al. 1994; Lafontaine et al. 1995). A signal corresponding to the modification was readily detected in wild-type strains whether grown in YPGal or YPD (Fig. 5B, lanes 1,2). For GAL::ZZ-dim2 strains, the modification was only detected in permissive conditions and at the early time points of transfer to glucose (Fig. 5B, lanes 3,4).

We concluded that Dim1p and Dim2p are associated in 


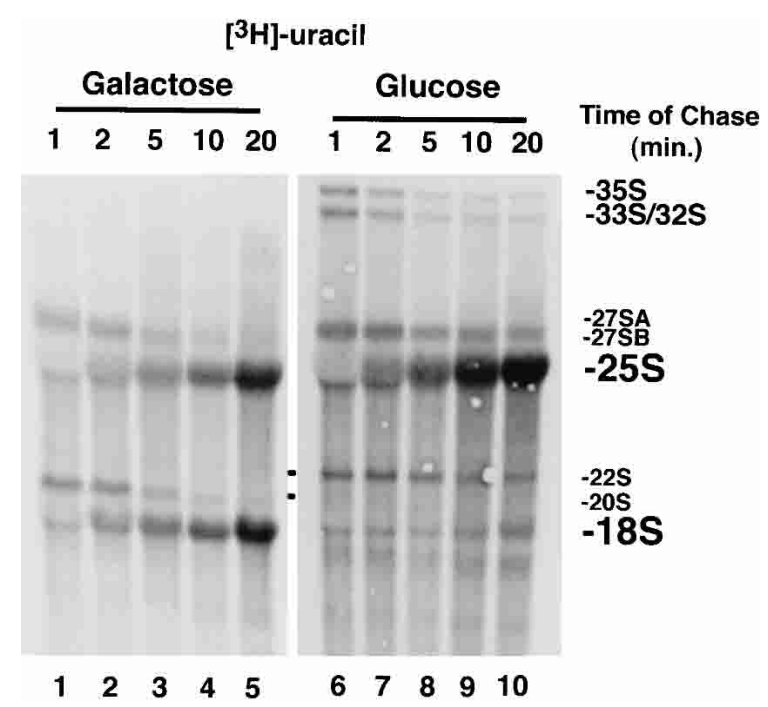

FIGURE 6. Pulse-chase labeling analysis of pre-rRNA processing in cells depleted for Dim2p. Cells expressing a $G A L$-regulated epitopetagged DIM2 construct (GAL::ZZ-dim2) were grown exponentially in complete medium, washed, and transferred to a glucose-based minimal medium lacking uracil for $19 \mathrm{~h}$ to achieve Dim2p depletion. Cells were pulse-labeled for $4 \mathrm{~min}$ with tritiated uracil and chased with an excess of cold uracil for up to $20 \mathrm{~min}$. Total RNA was extracted and processed, separated on denaturing agarose gels, and transferred to high resolution membranes. Membranes were sprayed with tritium enhancer and exposed to film. For comparison, the experiment was performed in galactose in parallel.

vivo and that pre-rRNAs accumulated in the absence of Dim2p are not methylated.

\section{Dim2p follows the preribosomes from early nucleolar to late cytoplasmic stages}

RNA partners of Dim2p were also inspected by coprecipitation. Interactions with nucleolar RNA species (35S and U3) and a cytoplasmic pre-rRNA (methylated 20S) were tested by primer extension, Northern-blot, and/or pCp labeling (Fig. 7B-D).

Glass-beads lysates from strains expressing a ZZ-Dim2p fusion were incubated with IgG-coated agarose beads in the presence of $150 \mathrm{mM}$ salts. RNA from the total (T), supernatant $(\mathrm{S})$, and pellet $(\mathrm{P})$ fractions was extracted and processed for primer extension (Fig. 7B), Northern-blot hybridization (Fig. 7C,D, top), or pCp labeling (Fig. 7D, bottom). Serial dilutions of the input were loaded to estimate the efficiency of recovery of the various RNAs coprecipitated. We concluded that Dim2p is tightly bound to the $35 \mathrm{~S}$, $20 \mathrm{~S}$, and methylated $20 \mathrm{~S}$ pre-rRNAs. By comparison, Rio2p, another component of the SSU RRP complex, was also stably associated with methylated $20 \mathrm{~S}$ pre-rRNAs but did not coprecipitate any $35 \mathrm{~S}$ RNA. A significant level $(\sim 5 \%)$ of interaction with the box C/D snoRNA U3 was also noted; other snoRNAs were not efficiently coprecipitated (data not shown).
In conclusion, the association of Dim2p with the $35 \mathrm{~S}$ and methylated 20S pre-rRNAs indicates that the protein joins the preribosomes at an early nucleolar stage and follows the particles to their site of final maturation in the cytoplasm.

\section{DISCUSSION}

\section{$\mathrm{KH}-$ proteins and ribosome synthesis}

The KH module is a well-characterized RNA binding domain, and unsurprisingly, $\mathrm{KH}$-proteins have been involved in most steps of gene expression (see Kiledjian et al. 1995; Ostareck-Lederer et al. 1998; Irie et al. 2002; Kong et al. 2003; Oleynikov and Singer 2003); however, very few had been involved in ribosome synthesis (Sasaki et al. 2000).

Conditional inactivation of Dim2p led to a severe prerRNA processing defect. Cleavage of the pre-rRNAs was inhibited at the early processing sites $\mathrm{A}_{1}$ and $\mathrm{A}_{2}$, leading to a substantial deficit in $20 \mathrm{~S}$ and $27 \mathrm{SA}_{2}$ pre-rRNAs and mature $18 \mathrm{~S}$ rRNA with the concomitant accumulation of an aberrant $22 \mathrm{~S}$ dead-end intermediate. This is similar to the phenotype described for cells depleted for Dim1p, a methyltransferase that selects two adjacent adenosines for $\mathrm{m}_{2}^{6} \mathrm{Am}_{2}^{6} \mathrm{~A}$ dimethylation at the $18 \mathrm{~S}$ rRNA $3^{\prime}$ terminal stemloop (Lafontaine et al. 1998 and references therein).

Dim2p is well conserved in eukaryotes, and orthologs are detected throughout the Archaeal domain of life. In addition, Dim2p shows striking homology with Krrlp, a eukaryotic-specific KH-protein involved in SSU synthesis (Sasaki et al. 2000). Other such couples of related nonredundant RRPs have been described, suggesting the possible handover of preribosomes from one partner to the next (e.g., the GTPases Bmslp and Tsrlp and the protein kinases Riolp and Rio2p; Gelperin et al. 2001; Vanrobays et al. 2001, 2003; Wegierski et al. 2001). A similar mechanism has been proposed for several RRPs homologous to RPs or translation factors (e.g., Rlp7p/Rpl7p, Imp3p/Rps9p, Yho52p/Rpllp, Rlp24p/Rpl24p, Efl1p/EF-2; for discussion, see Gadal et al. 2002).

\section{Dim2p follows the preribosomes from the nucleolus to the cytoplasm}

Subcellular distribution studies with a Dim2p-GFP construct demonstrated that the protein shows a highly dynamic behavior with respect to growth. The protein was detected both in the cytoplasm and the nucleus in exponentially growing cells and was concentrated to the nucleus and nucleolus as cells reached the stationary phase of growth. This suggested that Dim2p constantly shuttles between the nucle(ol)us and the cytoplasm and that this trafficking comes to a halt with the decreased need in ribosome synthesis that correlates with the stationary phase of growth. That Dim2p is indeed a nucleocytoplasmic shuttling protein was recently confirmed by its nuclear accumu- 
A.

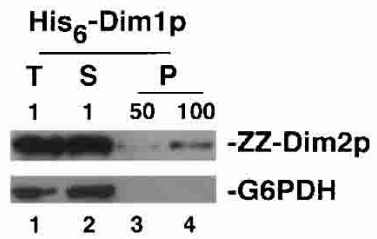

c.

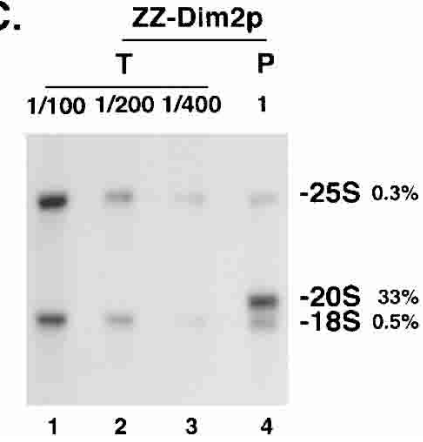

B.

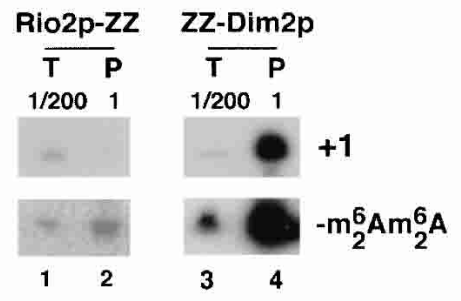

D.
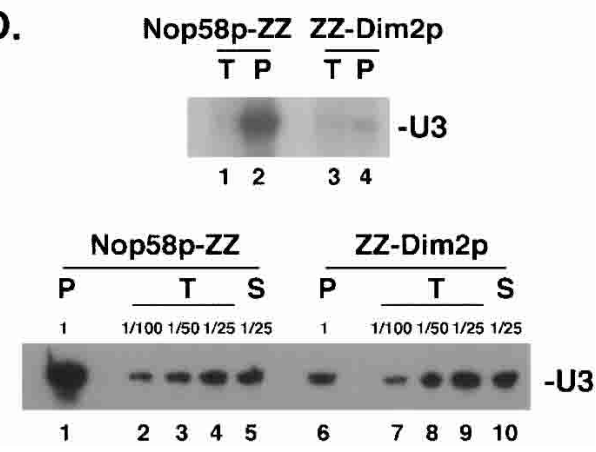

FIGURE 7. Protein and RNA partners of Dim2p. Dim2p is stably associated with the $18 \mathrm{~S}$ rRNA dimethyltransferase Dimlp as well as with the 35S primary transcripts, the 20S, and dimethylated $20 \mathrm{~S}$ pre-rRNAs. A significant level of interaction with the box C/D snoRNA U3 was also noted. (A) Dim2p is stably associated with Dimlp. A crude cell lysate from cells expressing a ZZ-Dim $2 \mathrm{p}$ fusion and $\mathrm{a} \mathrm{His}_{6}$-Dim $1 \mathrm{p}$ construct was incubated with metal affinity resin; the ZZ-Dim2p fusion was specifically recovered in the pellet fractions as detected by Western blotting with an antibody specific to the Protein A moiety of the fusion. As a control, an antibody specific to glucose-6-phosphate dehydrogenase (G6PDH) was used. $(B, C) \operatorname{Dim} 2 \mathrm{p}$ is specifically associated with early and late pre-rRNAs. Crude cell lysates from strains expressing a functional ZZ-Dim2p fusion were used in a coprecipitation experiment with IgG-coated agarose beads (see Material and Methods). RNA from the total (T), supernatant (S), and pellet (P) fractions were either used in a primer extension experiment that selectively select for the $35 \mathrm{~S}(+1)$ or the dimethylated $20 \mathrm{~S}$ pre-rRNAs (oligonucleotides h and c respectively, $B$ ) or processed for Northern-blot hybridization with probes specific to the 20S pre-rRNA and the mature $18 \mathrm{~S}$ and $25 \mathrm{~S}$ rRNAs $(C)$. Serial dilutions of the input were loaded as controls. $(C)$ Phospor Imager quantitation of the material recovered revealed that over one third of the total amount of $20 \mathrm{~S}$ pre-rRNA engaged in the pull-down assay was specifically coprecipitated with the ZZ-Dim2p fusion. For comparison, the low level of nonspecific coprecipitation observed for the mature rRNAs was of only $\sim 0.5 \%$ and $\sim 0.3 \%$ for the $18 \mathrm{~S}$ and $25 \mathrm{~S}$ rRNAs, respectively. (D) Dim2p interacts specifically with the box C/D snoRNA U3. Interaction between Dim2p and the snoRNAs was tested both by pCp-labeling (top) and Northern-blot (bottom). As a control, a strain expressing a core box C/D snoRNP protein (Nop58p-ZZ) was used.

lation in strains defective for transport (Schafer et al. 2003). Furthermore, coprecipitation experiments demonstrated that Dim2p is associated with early and late pre-rRNAs, that is, nucleolar $35 \mathrm{~S}$ primary transcripts and cytoplasmic methylated 20S pre-rRNAs. Collectively, these data indicate that Dim2p joins the preribosomes at an early nucleolar stage of assembly and follows the particles up to the cytoplasm.

\section{Could Dim2p recruit Dim1p to the preribosomes?}

The 18S rRNA dimethylation is a late modification that occurs on cytoplasmic $20 \mathrm{~S}$ pre-rRNAs; however, the methyltransferase involved is additionally required for nucleolar pre-rRNA cleavages. We therefore postulated that nucleolar pre-rRNA molecules that have bound Dimlp and are thus programmed for cytoplasmic modification are positively discriminated, in a quality-control mechanism, for process- ing at sites $\mathrm{A}_{1}$ and $\mathrm{A}_{2}$ (Lafontaine et al. 1998 and references therein).

The association of Dim2p with early nucleolar pre-rRNAs and late cytoplasmic species, as well as its interaction with Dim1p and its requirement for $18 \mathrm{~S}$ rRNA dimethylation, suggests that Dim2p could recruit Dim1p to the prerRNAs, a function that would be mediated by its $\mathrm{KH}$-domain and account for its requirement in pre-rRNA processing.

\section{A connection to proteasome function?}

The relocation of Dim2p to the nucleolus, which occurs as cells reach the stationary phase of growth, coincides with the well-characterized "diauxic shift" (fermentation-based growth is limited by the depletion of glucose in the medium; see Herman 2002). In these conditions, the rate of ribosome synthesis is severely reduced, providing a possible explanation for the reduced nucleocytoplasmic shuttling of Dim2p and its nucleolar accumulation. It is quite remarkable in this respect that Noblp (see below and Table 1), another component of the SSU RRP complex, is only detected in exponentially growing cells and is being degraded, notably by the action of the yeast proteasome, during the transition to the stationary phase (Tone et al. 2000).

A similar dynamic localization under different growth conditions was noted for Rix7p, a putative AAA-ATPase involved in LSU synthesis. Rix7p was mostly detected as a perinuclear rim in early-log phase, within the whole nucleus in mid-log and concentrated in the nucleolus in starved cells (Gadal et al. 2001). Importantly, this effect is not generic to the RRPs, as the conditions of growth did not affect the nucleolar localization of other SSU RRP such as Riolp, Rio2p, Nop1p, Garlp, and Nsr1p (E. Vanrobays and D.L.J. Lafontaine, unpubl.) and the LSU RRP (Noclp; Milkereit et al. 2001).

Several lines of evidence suggest the existence of connections between small ribosomal subunit synthesis and proteasome function: (1) the Nin one binding protein (Nob1p), was originally isolated in a two-hybrid screen with Nin1p/Rpn12p, a subunit of the regulatory particle of the yeast proteasome (Tone and Toh 2002); (2) Dim2p is also known as Partner of Noblp (Pnolp) and interacts physically both in two-hybrid and coprecipitation with Noblp 
(Tone and Toh 2002); both Noblp and Pnolp are required for proteasome biogenesis; (3) Krrlp was identified in a two-hybrid screen using Tomlp, a putative ubiquitine ligase, as a bait (Sasaki et al. 2000); and (4) the ribosomal proteins RPS0A/B, which are required for 18S rRNA synthesis, interact functionally with Tom1p (Tabb et al. 2001).

These interactions between SSU RRP components, proteasome subunits, and a putative ubiquitin ligase, suggest that the proteasome could be recruited to misassembled preribosomes, stalled in maturation, in order to trigger the rapid degradation of the associated proteins.

While this manuscript was in its final stage of preparation, Dim2p (Rrp20p) was isolated in a screen for mutants that die on loss of mitochondrial DNA (Senapin et al. 2003) and characterized in a large-scale proteomic analysis (Peng et al. 2003). Strikingly, a single amino acid substitution in the KH-domain $(\mathrm{G} 235 \mathrm{~N})$ of Rrp20p led to a severe slowgrowth phenotype at all temperatures tested, demonstrating the importance of this motif for protein function (Senapin et al. 2003).

\section{MATERIAL AND METHODS}

\section{Sequence analysis}

The multiple alignment presented in Figure 3 was performed with Multalign (http://prodes.toulouse.inra.fr/multalin/multalin). Phylogeny was addressed with PhTree (http://www.genebee. msu.su/ services/phtree_reduced.html). Archaeal genomes were searched with COG at NCBI (http://www.ncbi.nlm.nih.gov/COG/). SMART (http://smart.embl-heidelberg.de/) was used to localize the $\mathrm{KH}$ domain.

\section{Yeast}

Yeast media were standard yeast extract/peptone (YP) supplemented with either glucose (YPD) or galactose and sucrose (YPGal; $2 \%$ of each) and minimal yeast nitrogen base (YNB), supplemented with amino acids and bases as required. Fluoro-orotateresistant clones were selected on YNB proline medium containing $0.6 \mathrm{~g} / \mathrm{L}$ fluoro-orotic acid (5-FOA).

Yeast strains were as follows: YO590, a/ $\alpha$ ura3-52/ura3-52 LEU2/LEU2 TRP1/TRP1 his3D200/HIS3 DIM2-GFP:KANMX6/

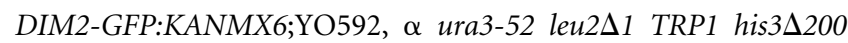

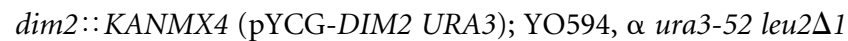
TRP1 HIS3 (a generous gift from B. Winsor [Strasbourg, France];

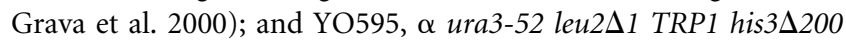
$\operatorname{dim} 2::$ KANMX4 (pGal::ZZ-DIM2 LEU2); YO596, $\alpha$ ura3-52

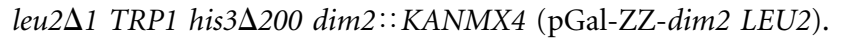

\section{DNA constructs}

Plasmid pGAL::ZZ-dim2 was constructed by PCR-directed homologous recombination as previously described (Oldenburg et al. 1997). Plasmid pGALPATA1L (CEN, ARS, LEU2) (a generous gift from K. Hellmuth and E. Hurt [Heidelberg, Germany]) was lin- earized with NcoI, and the DIM2 open reading frame was PCRamplified ( $p f u$ polymerase Promega) from wild-type genomic DNA with the oligonucleotides $3^{\prime}$-YOR145c, ATAGATCTCTCGAG CT CGAAT TCGGAT CCCCGGGGCCTCCATGGCCAT AAGCC CACAAATTATGTTTA and 5'-YOR145c, TTCGATATCCCAAC GACCGAAAACCTGTATTTTCAGGGCGC-

CCATATGGTTGCG

CCTACTGCTTTGAA, flanked on the $5^{\prime}$ and $3^{\prime}$ ends by homologous sequences to plasmid pGALPATA1L. The linearized plasmid and PCR fragment were cotransformed into strain YO592; transformants were selected for leucine prototrophy and resistance to 5-FOA on glucose.

A functional His6-Dimlp fusion was generated by PCR and cloned into pFL39 (ARS/CEN-TRP1).

\section{RNA methods}

RNA isolation, Northern-blot hybridization, primer extension, and in vivo pulse-chase labeling experiments were essentially carried out as described previously (Tollervey 1987; Tollervey et al. 1991). The oligonucleotide probes used for Northern-blot hybridizations (Fig. 1A) were as follows: a, CACCCATTCCCTCTTGC TAG; b, CATGGCTTAATCTTTGAGAC; c, TTAAGCGCAGGC CCGGCTGG; d, GATTGCTCGAATGCCCAAAG; e, TGCGTTC AAAGATTCGATG; f, GGCCAGCAATTTCAAGTTA; g, CTCAC GACGGTCTAAACCC; and h, ggcagatctgacgatcacc.

For the pulse-chase labeling, strain YO595 (GAL::ZZ-dim2) was pregrown at $30^{\circ} \mathrm{C}$ in YPGal medium and shifted to YPD for 12 h. Cells were washed and allowed for an addition $7 \mathrm{~h}$ of growth in minimal YNB medium (either glucose- or galactose-based) with uracil before being washed and shifted to identical media lacking uracil. Five milliliters of cultures was aliquoted and labeled for 4 min with $150 \mu \mathrm{Ci}\left\{{ }^{3} \mathrm{H}\right\}$-uracil; $0.6 \mathrm{~mL}$ cold uracil at $2 \mathrm{mg} / \mathrm{mL}$ was added, and $1 \mathrm{ml}$ samples were collected at 1,3, 5, 10, and $20 \mathrm{~min}$ and processed as described in Tollervey et al. (1991). 3'-end labeling was performed as described in Ganot et al. (1997).

\section{Glycerol gradients analysis}

Total yeast extracts and sedimentation profiles on $10 \%$ to $30 \%$ glycerol gradients were prepared as described in Vanrobays et al. (2003); 18 fractions were collected manually from the top of the gradients.

\section{Western blot analysis}

Proteins from total extracts, gradient fractions, or coprecipitation experiments were separated on $12 \%$ poly-acrylamide/SDS gels and transferred to Hybond-C membranes (AmershamBioSciences). GFP was detected by using a mouse monoclonal anti-GFP antibody (Roche) diluted at 1:1000; ribosomal proteins rpL3 and rpS8 were detected with a mouse monoclonal anti-rpL3 antiboby diluted at 1:5000 and a rabbit polyclonal anti-rpS8 antiboby diluted at 1:2000 (a kind gift from J. Warner, Albert Einstein, New York, and from G. Dieci, University of Parma, respectively). Protein $\mathrm{A}(\mathrm{ZZ})$-epitope tagged proteins were detected with the rabbit HRP conjugated anti-Protein A antibody (PAP, Dako SA) diluted at 1:5000. Zwf1p/G6PDH was detected with a rabbit polyclonal an- 
tibody (Sigma) at the working dilution of 1:1000. The ECL kit (AmershamBioSciences) was used for detection.

\section{Coprecipitation}

Coprecipitation were performed exactly as described in Vanrobays et al. (2003). The Talon metal affinity resin (BD, Clontech) was used for the $\mathrm{His}_{6}$-Dimlp experiment.

\section{Microscopy}

A Leica (DMRB) microscope equipped with a Coolsnap-CCD camera was used to take the pictures.

\section{ACKNOWLEDGMENTS}

Giovanna Jaramillo-Gutierrez (IBMM, ULB) is acknowledged for Northern-blot hybridizations and PhosphorImager quantitations; Sebastien Ferreira-Cerca, for support in the initial stages of this work. We thank Barbara Winsor (IBMC, CNRS, Strasbourg), Jonathan Warner (Albert Einstein, NY), and K. Hellmuth and E. Hurt (BZH, Heidelberg) for sharing valuable material; Yves Henry (LBME, CNRS, Toulouse), Stephan Visser, and Luis-Antonio Urrestarazu (IBMM, ULB), for helpful comments and critical reading of the manuscript. Research in MCF Laboratory is supported by the CNRS, the Université Paul Sabatier, and grants from the 'Programme de Recherche Fondamentale en Microbiologie et Maladies Infectieuses et Parasitaires du Ministère de l'Education Nationale' (MENRT) and ACI Microbiology. Research in DLJL Laboratory is supported by the Fonds National de la Recherche Scientifique, Université Libre de Bruxelles, and the following private charities: Alice and David van Buuren and Defay and Banque Nationale de Belgique. E.V. was supported by University Paul Sabatier and the EMBO (fellowship ALTF728-2002).

The publication costs of this article were defrayed in part by payment of page charges. This article must therefore be hereby marked "advertisement" in accordance with 18 USC section 1734 solely to indicate this fact.

Received August 21, 2003; accepted December 26, 2003.

\section{REFERENCES}

Adinolfi, S., Bagni, C., Castiglione Morelli, M.A., Fraternali, F., Musco, G., and Pastore, A. 1999. Novel RNA-binding motif: The KH module. Biopolymers 51: 153-164.

Allmang, C., Mitchell, P., Petfalski, E., and Tollervey, D. 2000. Degradation of ribosomal RNA precursors by the exosome. Nucleic Acids Res. 28: 1684-1691.

Burd, C.G. and Dreyfuss, G. 1994. Conserved structures and diversity of functions of RNA-binding proteins. Science 265: 615-621.

Chan, H.Y., Brogna, S., and O'Kane, C.J. 2001. Dribble, the Drosophila KRR1p homologue, is involved in rRNA processing. Mol. Biol. Cell. 12: 1409-1419.

Chen, W., Bucaria, J., Band, D.A., Sutton, A., and Sternglanz, R. 2003. Enp1, a yeast protein associated with U3 and U14 snoRNAs, is required for pre-rRNA processing and 40S subunit synthesis. Nucleic Acids Res. 31: 690-699.

De Boulle, K., Verkerk, A.J., Reyniers, E., Vits, L., Hendrickx, J., Van Roy, B., Van den Bos, F., de Graaff, E., Oostra, B.A., and Willems,
P.J. 1993. A point mutation in the FMR-1 gene associated with fragile X mental retardation. Nat. Genet. 3: 31-35.

Dragon, F., Gallagher, J.E., Compagnone-Post, P.A., Mitchell, B.M., Porwancher, K.A., Wehner, K.A., Wormsley, S., Settlage, R.E., Shabanowitz, J., Osheim, Y., et al. 2002. A large nucleolar U3 ribonucleoprotein required for $18 \mathrm{~S}$ ribosomal RNA biogenesis. Nature 417: 967-970.

Fatica, A. and Tollervey, D. 2002. Making ribosomes. Curr. Opin. Cell Biol. 14: 313-318.

Fatica, A., Oeffinger, M., Dlakic, M., and Tollervey, D. 2003. Nob1p is required for cleavage of the $3^{\prime}$ end of $18 \mathrm{~S}$ rRNA. Mol. Cell. Biol. 23: $1798-1807$.

Gadal, O., Strauss, D., Braspenning, J., Hoepfner, D., Petfalski, E., Philippsen, P., Tollervey, D., and Hurt, E. 2001. A nuclear AAAtype ATPase (Rix7p) is required for biogenesis and nuclear export of 60 S ribosomal subunits. EMBO J. 20: 3695-3704.

Gadal, O., Strauss, D., Petfalski, E., Gleizes, P.E., Gas, N., Tollervey, D., and Hurt, E. 2002. Rlp7p is associated with 60S preribosomes, restricted to the granular component of the nucleolus, and required for pre-rRNA processing. J. Cell. Biol. 157: 941-951.

Ganot, P., Caizergues-Ferrer, M., and Kiss, T. 1997. The family of box ACA small nucleolar RNAs is defined by an evolutionarily conserved secondary structure and ubiquitous sequence elements essential for RNA accumulation. Genes Dev. 11: 941-956.

Gavin, A.C., Bosche, M., Krause, R., Grandi, P., Marzioch, M., Bauer, A., Schultz, J., Rick, J.M., Michon, A.M., Cruciat, C.M., et al. 2002. Functional organization of the yeast proteome by systematic analysis of protein complexes. Nature 415: 141-147.

Gelperin, D., Horton, L., Beckman, J., Hensold, J., and Lemmon, S.K. 2001. Bmslp, a novel GTP-binding protein, and the related Tsrlp are required for distinct steps of $40 \mathrm{~S}$ ribosome biogenesis in yeast. RNA 7: 1268-1283.

Gibson, T.J., Rice, P.M., Thompson, J.D., and Heringa, J. 1993a. KH domains within the FMR1 sequence suggest that fragile $\mathrm{X}$ syndrome stems from a defect in RNA metabolism. Trends Biochem. Sci. 18: 331-333.

Gibson, T.J., Thompson, J.D., and Heringa, J. 1993b. The KH domain occurs in a diverse set of RNA-binding proteins that include the antiterminator NusA and is probably involved in binding to nucleic acid. FEBS Lett. 324: 361-366.

Grandi, P., Rybin, V., Bassler, J., Petfalski, E., Strauss, D., Marzioch, M., Schafer, T., Kuster, B., Tschochner, H., Tollervey, D., et al. 2002. $90 \mathrm{~S}$ pre-ribosomes include the $35 \mathrm{~S}$ pre-rRNA, the U3 snoRNP, and 40S subunit processing factors but predominantly lack 60S synthesis factors. Mol. Cell 10: 105-115.

Grava, S., Dumoulin, P., Madania, A., Tarassov, I., and Winsor, B. 2000. Functional analysis of six genes from chromosomes XIV and $\mathrm{XV}$ of Saccharomyces cerevisiae reveals YOR145c as an essential gene and YNL059c/ARP5 as a strain-dependent essential gene encoding nuclear proteins. Yeast 16: 1025-1033.

Grishin, N.V. 2001. KH domain: One motif, two folds. Nucleic Acids Res. 29: 638-643.

Henry, Y., Wood, H., Morrissey, J.P., Petfalski, E., Kearsey, S., and Tollervey, D. 1994. The $5^{\prime}$ end of yeast $5.8 \mathrm{~S}$ rRNA is generated by exonucleases from an upstream cleavage site. EMBO J. 13:24522463.

Herman, P.K. 2002. Stationary phase in yeast. Curr. Opin. Microbiol. 5: 602-607.

Ho, Y., Gruhler, A., Heilbut, A., Bader, G.D., Moore, L., Adams, S.L., Millar, A., Taylor, P., Bennett, K., Boutilier, K., et al. 2002. Systematic identification of protein complexes in Saccharomyces cerevisiae by mass spectrometry. Nature 415: 180-183.

Ihmels, J., Friedlander, G., Bergmann, S., Sarig, O., Ziv, Y., and Barkai, N. 2002. Revealing modular organization in the yeast transcriptional network. Nat. Genet. 31: 370-377.

Irie, K., Tadauchi, T., Takizawa, P.A., Vale, R.D., Matsumoto, K., and Herskowitz, I. 2002. The Khd1 protein, which has three KH RNAbinding motifs, is required for proper localization of ASH1 mRNA in yeast. $E M B O ~ J . ~ 21: ~ 1158-1167$. 
Kiledjian, M., Wang, X., and Liebhaber, S.A. 1995. Identification of two $\mathrm{KH}$ domain proteins in the $\alpha$-globin mRNP stability complex. EMBO J. 14: 4357-4364.

Kiss, T. 2002. Small nucleolar RNAs: An abundant group of noncoding RNAs with diverse cellular functions. Cell 109: 145-148.

Kong, J., Ji, X., and Liebhaber, S.A. 2003. The KH-domain protein $\alpha$ $\mathrm{CP}$ has a direct role in mRNA stabilization independent of its cognate binding site. Mol. Cell Biol. 23: 1125-1134.

Kressler, D., Linder, P., and de la Cruz, J. 1999. Protein trans-acting factors involved in ribosome biogenesis in Saccharomyces cerevisiae. Mol. Cell. Biol. 19: 7897-7912.

Lafontaine, D.L.J. 2004. Eukaryotic ribosome synthesis. In Protein synthesis and ribosome structure (ed. K. Nierhaus). Wiley-InterScience (in press).

Lafontaine, D.L.J. and Tollervey, D. 2001. The function and synthesis of ribosomes. Nat. Rev. Mol. Cell. Biol. 2: 514-520.

Lafontaine, D., Vandenhaute, J., and Tollervey, D. 1995. The $18 \mathrm{~S}$ rRNA dimethylase Dimlp is required for pre-ribosomal RNA processing in yeast. Genes Dev. 9: 2470-2481.

Lafontaine, D.L.J., Preiss, T., and Tollervey, D. 1998. Yeast 18S rRNA dimethylase Dimlp: A quality control mechanism in ribosome synthesis? Mol. Cell. Biol. 18: 2360-2370.

Liu, P.C. and Thiele, D.J. 2001. Novel stress-responsive genes EMG1 and NOP14 encode conserved, interacting proteins required for 40S ribosome biogenesis. Mol. Biol. Cell. 12: 3644-3657.

Milkereit, P., Gadal, O., Podtelejnikov, A., Trumtel, S., Gas, N., Petfalski, E., Tollervey, D., Mann, M., Hurt, E., and Tschochner, H. 2001. Maturation and intranuclear transport of pre-ribosomes requires noc proteins. Cell 105: 499-509.

Oldenburg, K.R., Vo, K.T., Michaelis, S., and Paddon, C. 1997. Recombination-mediated PCR-directed plasmid construction in vivo in yeast. Nucleic Acids Res. 25: 451-452.

Oleynikov, Y. and Singer, R.H. 2003. Real-time visualization of ZBP1 association with $\beta$-actin mRNA during transcription and localization. Curr. Biol. 13: 199-207.

Ostareck-Lederer, A., Ostareck, D.H., and Hentze, M.W. 1998. Cytoplasmic regulatory functions of the $\mathrm{KH}$-domain proteins hnRNPs K and E1/E2. Trends Biochem. Sci. 23: 409-411.

Peng, W.T., Robinson, M.D., Mnaimneh, S., Krogan, N.J., Cagney, G., Morris, Q., Davierwala, A.P., Grigull, J., Yang, X., Zhang, W., et al. 2003. A panoramic view of yeast noncoding RNA processing. Cell 113: 919-933.

Raue, H.A. 2003. Pre-ribosomal RNA processing and assembly in Saccharomyces cerevisiae. In The nucleolus (ed. M.O. Olson). http:// www.eurekah.com.

Sasaki, T., Toh, E.A., and Kikuchi, Y. 2000. Yeast Krrlp physically and functionally interacts with a novel essential Krilp, and both proteins are required for $40 \mathrm{~S}$ ribosome biogenesis in the nucleolus. Mol. Cell. Biol. 20: 7971-7979.

Schafer, T., Strauss, D., Petfalski, E., Tollervey, D., and Hurt, E. 2003. The path from nucleolar $90 \mathrm{~S}$ to cytoplasmic $40 \mathrm{~S}$ pre-ribosomes. EMBO J. 22: 1370-1380.
Senapin, S., Clark-Walker, G.D., Chen, X.J., Seraphin, B., and Daugeron, M.C. 2003. RRP20, a component of the 90S preribosome, is required for pre-18S rRNA processing in Saccharomyces cerevisiae. Nucleic Acids Res. 31: 2524-2533.

Siomi, H., Matunis, M.J., Michael, W.M., and Dreyfuss, G. 1993. The pre-mRNA binding K protein contains a novel evolutionarily conserved motif. Nucleic Acids Res. 21: 1193-1198.

Siomi, H., Choi, M., Siomi, M.C., Nussbaum, R.L., and Dreyfuss, G. 1994. Essential role for $\mathrm{KH}$ domains in RNA binding: Impaired RNA binding by a mutation in the $\mathrm{KH}$ domain of FMR1 that causes fragile X syndrome. Cell 77: 33-39.

Tabb, A.L., Utsugi, T., Wooten-Kee, C.R., Sasaki, T., Edling, S.A., Gump, W., Kikuchi, Y., and Ellis, S.R. 2001. Genes encoding ribosomal proteins Rps0A/B of Saccharomyces cerevisiae interact with TOM1 mutants defective in ribosome synthesis. Genetics 157: $1107-1116$.

Tollervey, D. 1987. A yeast small nuclear RNA is required for normal processing of pre-ribosomal RNA. EMBO J. 6: 4169-4175.

Tollervey, D., Lehtonen, H., Carmo-Fonseca, M., and Hurt, E.C. 1991. The small nucleolar RNP protein NOP1 (fibrillarin) is required for pre-rRNA processing in yeast. EMBO J. 10: 573-583.

Tone, Y. and Toh, E.A. 2002. Noblp is required for biogenesis of the $26 \mathrm{~S}$ proteasome and degraded upon its maturation in Saccharomyces cerevisiae. Genes Dev. 16: 3142-3157.

Tone, Y., Tanahashi, N., Tanaka, K., Fujimuro, M., Yokosawa, H., and Toh-e, A. 2000. Nob1p, a new essential protein, associates with the $26 \mathrm{~S}$ proteasome of growing Saccharomyces cerevisiae cells. Gene 243: $37-45$.

Trapman, J., Retel, J., and Planta, R.J. 1975. Ribosomal precursor particles from yeast. Exp. Cell. Res. 90: 95-104.

Tschochner, H. and Hurt, E. 2003. Pre-ribosomes on the road from the nucleolus to the cytoplasm. Trends Cell. Biol. 13: 255-263.

Udem, S.A. and Warner, J.R. 1973. The cytoplasmic maturation of a ribosomal precursor ribonucleic acid in yeast. J. Biol. Chem. 248: 1412-1416.

Vanrobays, E., Gleizes, P.E., Bousquet-Antonelli, C., Noaillac-Depeyre, J., Caizergues-Ferrer, M., and Gelugne, J.P. 2001. Processing of $20 \mathrm{~S}$ pre-rRNA to $18 \mathrm{~S}$ ribosomal RNA in yeast requires Rrp10p, an essential non-ribosomal cytoplasmic protein. EMBO J. 20: 4204-4213.

Vanrobays, E., Gelugne, J.P., Gleizes, P.E. and Caizergues-Ferrer, M. 2003. Late Cytoplasmic maturation of the small ribosomal subunit requires RIO proteins in Saccharomyces cerevisiae. Mol. Cell. Biol. 23: 2083-2095.

Vazquez, A., Flammini, A., Maritan, A., and Vespignani, A. 2003. Global protein function prediction from protein-protein interaction networks. Nat. Biotechnol. 21: 697-700.

Venema, J. and Tollervey, D. 1999. Ribosome synthesis in Saccharomyces cerevisiae. Ann. Rev. Genet. 33: 261-311.

Wegierski, T., Billy, E., Nasr, F., and Filipowicz, W. 2001. Bms1p, a G-domain-containing protein, associates with Rcllp and is required for $18 \mathrm{~S}$ rRNA biogenesis in yeast. RNA 7: 1254-1267. 

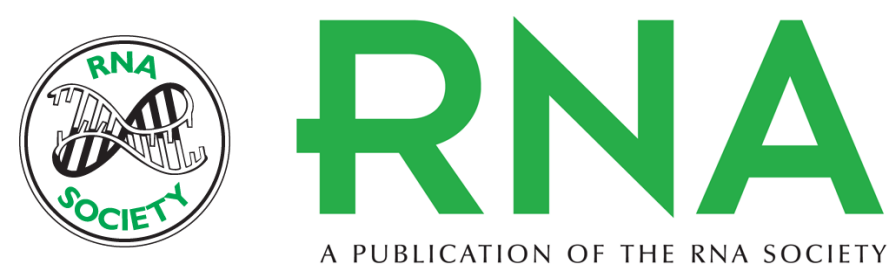

A PUBLICATION OF THE RNA SOCIETY

\section{Dim2p, a KH-domain protein required for small ribosomal subunit synthesis}

EMMANUEL VANROBAYS, JEAN-PAUL GÉLUGNE, MICHÈLE CAIZERGUES-FERRER, et al.

RNA 2004 10: 645-656

References This article cites 55 articles, 21 of which can be accessed free at: http://rnajournal.cshlp.org/content/10/4/645.full.html\#ref-list-1

\section{License}

Email Alerting Receive free email alerts when new articles cite this article - sign up in the box at the Service top right corner of the article or click here. 